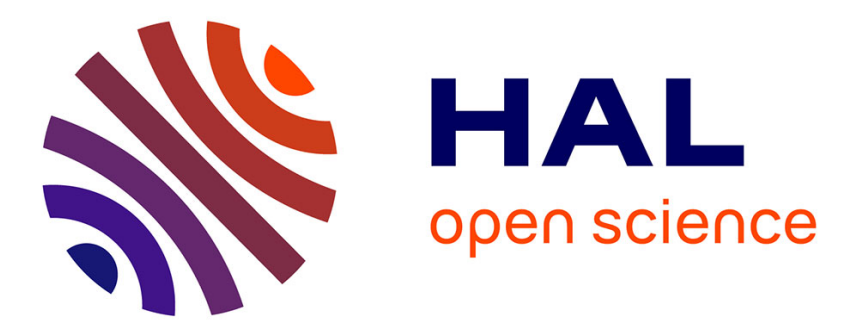

\title{
Probabilistic Modelling of Compressive Strength of Concrete Using Response Surface Methodology and Neural Networks
}

S.M.A. Boukli Hacene, Fouad Ghomari, Franck Schoefs, Abdelhafid Khelidj

\section{- To cite this version:}

S.M.A. Boukli Hacene, Fouad Ghomari, Franck Schoefs, Abdelhafid Khelidj. Probabilistic Modelling of Compressive Strength of Concrete Using Response Surface Methodology and Neural Networks. Arabian Journal for Science and Engineering, 2014, 39 (6), pp.4451-4460. 10.1007/s13369-014-1139y . hal-01968850

\section{HAL Id: hal-01968850 https://hal.science/hal-01968850}

Submitted on 3 Jan 2019

HAL is a multi-disciplinary open access archive for the deposit and dissemination of scientific research documents, whether they are published or not. The documents may come from teaching and research institutions in France or abroad, or from public or private research centers.
L'archive ouverte pluridisciplinaire HAL, est destinée au dépôt et à la diffusion de documents scientifiques de niveau recherche, publiés ou non, émanant des établissements d'enseignement et de recherche français ou étrangers, des laboratoires publics ou privés. 


\title{
Probabilistic Modelling of Compressive Strength of Concrete Using Response Surface Methodology and Neural Networks
}

\author{
S. M. A. BOUKLI HACENE ${ }^{(1)} *$, F. GHOMARI $^{(1)}$, F. SCHOEFS $^{(2)}$, A. KHELIDJ $^{(3)}$
}

${ }^{(1)}$ Laboratory EOLE, Department of Civil Engineering, Faculty of Technology, Abou Bekr Belkaid University, B.P. 230 Chetouane, Tlemcen 13000, Algeria boukli_ma@yahoo.fr,ghomarifouad@yahoo.fr

${ }^{(2)}$ GeM (UMR CNRS 6183) - Faculty of Science and Techniques, University of Nantes, 2, rue de la Houssinière, B.P. 92208, 44322 Nantes Cedex 3, France franck.schoefs@univ-nantes.fr

${ }^{(3)}$ GeM (UMR CNRS 6183) - IUT of Saint-Nazaire, University of Nantes, 58, rue MichelAnge, B.P. 420, 44606 Saint-Nazaire Cedex, France

abdelhafid.khelidj@univ-nantes.fr

* Corresponding author. Tel.: 00213551931095.

E-mail address: boukli_ma@yahoo.fr (S. M. A. Boukli Hacene).

\begin{abstract}
In this paper we aim to achieve a probabilistic modelling of the compressive strength of concrete using three Response Surface Models (RSM) and the Artificial Neural Network method (ANN). The Input random variables for the three RSM and for the ANN are: cement content, water content, measure of slump and air content, while the output for all the models is the compressive strength of concrete at 28 days.
\end{abstract}


More than 800 cylindrical specimens $16 \times 32 \mathrm{~cm}$ were tested. These experimental data are used to check the reliability of the suggested probabilistic models and their capability of prediction. It is shown that the use of these new RSM is as simple as that of any of the basic formulas, yet they provide an improved tool for the prediction of concrete strength and for concrete proportioning. We also show that the concrete compressive strength could be readily and accurately estimated from the established ANN.

Key words: Concrete, Response Surface Methodology, Artificial Neural Networks, Cement content, Compressive strength, Air content, Local materials, Slump, Water content.

\section{INTRODUCTION}

The compressive strength of the concrete is generally seen as its more significant property for designing new structures although, in many practical cases, other characteristics such as diffusivity and permeability are significant too for the durability prediction. Nevertheless, the compressive strength generally projects a global image of the quality of the concrete since it is directly connected to the structure of the paste of the hydrated cement. Moreover, the resistance of the concrete is almost invariably the key element at the time of the structural design and when establishing the specifications of conformity (Neville, 1995). Since several decades may and be centuries, the relation between the composition of the concrete and its compressive strength has interested the researchers. However no fundamental and universally adopted theory exists on the matter, beyond the common concept of the water/cement ratio $(\mathrm{W} / \mathrm{C})$.

Abrams (1919) was the first to highlight the importance of this parameter on which the compressive strength depends, while, twenty years before, Féret (1892) envisaged resistances (in traction and compression) according to the voluminal concentration of cement in the 
paste. However, although the ratio $\mathrm{W} / \mathrm{C}$ is a basic concept in technology of the concrete, it is not sufficient for a complete control of the compressive strength. Other parameters are necessary (Popovics, 1990) if engineers aim to predict concrete strength with a relative precision of few percents: the resources being limited, an optimisation of their use is needed and this goal must be achieved progressively. They are properties narrowly dependent on purely local conditions, such as the properties of its components, as well as the properties in its fresh state (slump, content air) (Ferkous et col., 1999; Boukli Hacene et col., 2009).

For usual ratios W/C (or cement mixture), the three models of compressive strength of Féret, Bolomey and Abram gives close forecasts. According to de Larrard (2000), the formula of Féret, has four advantages however: It refers to the volume of cement, which is a physical parameter, while the ratio $\mathrm{W} / \mathrm{C}$ is only one indicator, without direct physical significance; it takes into account the volume of air; it has a mathematical form which can be justified physically and it gives realistic values when the quantity of cement is extrapolated. This report is still true for the formula of Abrams, but it is not any more for that of Bolomey which envisages a negative resistance for the ratios water/ciment higher than 2. More significant, this last relation envisages a resistance which tends towards infinity for very weak ratios W/C. However, with other data, the equation of Féret always does not give such a satisfactory agreement. That is due to the fact that the compressive strength of the concrete is not solely controlled by the resistance of the paste. Limits can be found in the deterministic approach of this problem where a lot of sources of heterogeneity and variability are missed.

Two approaches can be investigated:

- development of complex models based on fracture mechanics and water-grain interaction with taking into account chemical forces;

- development of a family of comprehensive models that are fitted on data- bases with a special care to the variability. 
The purpose of this paper is to express some effects quantitatively for the improvement of the accuracy of the models following the second approach. More specifically the effects of some of these secondary factors on concrete strength are analyzed in this paper, especially those of the water and cement contents which are, by the way, interrelated. Two types of Meta-Models are suggested:

- the Response Surface Method that lies on the fitting on a data bate built from an experimental plan based on probabilistic distribution of input parameters,

- the Architecture of Artificial Neural Network that nourishes of the same inputs but with a neuronal approach to fit the reality.

Even if the scientific bases of these models are different, they show their disposal to represent complex responses in an hazard context. They are here selected to show improved correlations with experimental strength data. Also, an interpretation of the new formulas is offered that reveals greater roles of the quantities of mixing water and/or cement in concrete strength than reflected solely by ratio $\mathrm{W} / \mathrm{C}$. This recognition provides an indirect contribution to a better understanding of the role of composition in the strength and fracture of concrete.

One can also use the water content, cement content, air content, a measure of slump by raising these terms to a higher power, or any combination of these. All these variables are either parameters of formulation either observations (air content and slump). In the following they are all considered as inputs to improve the consistency of the model. Then, statistical analysis will show if the established formulas are supported by experimental data better than the basic model, and if so, which formulas approximate the experimental results best. This elementary statistical approach is justified because all the strength-predicting formulas are essentially empirical. 


\section{PHYSICALLY GOVERNED EXPERIMENTAL PLAN: SELECTED BASIC DATA BASE AND SENSE IN TERMS OF VARIABILITY}

The first step of our approach is to establish a convenient and rich data base that could reflect the variability of a concrete realized with local materials. Knowing the importance of the proportions of cement and the ratio $\mathrm{W} / \mathrm{C}$ on the characteristics of the concrete in fresh and hardened states, we have chosen to vary these two parameters according to the flow chart presented in Figure 1, which led us to the realization of 18 formulations of concrete. It assumed that $\mathrm{W}$ and $\mathrm{C}$ are uniformly distributed thus the experimental plans contains the same number of samples in each formulation. That allows us to give the same weight to each formulation and to ask the probabilistic modelling to fit the reality whatever $\mathrm{W} / \mathrm{C}$ ratio and Cement mixture: that is why, a uniform distribution of these random data could be interesting.

Fig. 1. Organigram of the experimental program.

We have also used two modes of maturation; the cylindrical specimens $16 \times 32 \mathrm{~cm}$ were preserved after preparing and removal from the mould either out in the open or completely immersed in water (NA 426).

The reproducibility of the test of compression is very difficult to reach, since the sources of errors concerning this test are multiple: it is often enough that one of the specifications is not followed during the test, to obtain an aberrant result. This is why we studied, for each parameter, twenty cylindrical specimens instead of the three conventional ones. So, the average strength $\underline{\mathrm{S}}$ is obtained on approximately twenty or so tests on cylindrical specimens and this after having rejected the few aberrant values by using the test tabular of the normal law (Favre, 2004): it leads to reject values that are not conform in terms of quality control i.e. 
that are out of the interval $[\underline{S}-3 \sigma \underline{S}+3 \sigma]$. Thus we get realizations having a sense with quality controls: this is a very important issue when performing probabilistic modelling. Statistical analysis and probabilistic modelling can be performed only within a quality warranty. Thus the data-base we use in the following contains about 800 realizations. Within the framework of our study, the volumes of air were measured with an aerometer of concrete (standard NF P 18-353) and the slumps also measured using the slump test (standard NF P 18-451), thus air content and slump are in this case imposed by physics.

The concretes carried out were made in accordance with the standards in use [Algerian Standards, 1992; AFNOR, 2002]. The materials dried beforehand in the drying oven with $110 \pm 5 \mathrm{C}$, are introduced into the concrete-mixer in the following order: gravels $(16 / 25,8 / 16$, 3/8), cement, sand and water. After a dry mixing about one minute, we add water mixing and we continue mixing during 2 minutes. The installation in the cylindrical specimens took place, by vibration or, by pricking, according to the test results of slump and in accordance with the NF P 18-421, 422, 423 standards.

\section{SUGGESTED MODELS}

\subsection{Main concepts of Response Surface Methodology}

Nowadays, quite a lot of response surface functions have been tested in several areas. We generally distinguish two types of models (Schoefs, 2008; Baroth, 2011): the physical response function and the analytical response function. We focus here on the second one and more especially on the polynomial models of order less than 3 with or without interaction terms (Faravelly, 1989; Labeyrie, 1997). That allows keeping asymptotic behaviour with a physical meaning where only few experiments are available (distribution tails) (Leira, 2003). The general form of the full quadratic response surface is the following 


$$
\mathrm{Y}=\mathbf{a} \mathrm{X}
$$

Where $\mathrm{Y}$ is the random response, a the vector of coefficients and $\mathrm{X}$ the vector of random variables and products of them.

$$
\begin{gathered}
f_{c 28}=b_{0}+b_{1} S+b_{2} A-b_{3} W+b_{4} C+b_{5} S A- \\
-b_{6} S W+b_{7} S C-b_{8} A W-b_{9} A C-b_{10} W C+ \\
+b_{11} S^{2}-b_{12} A^{2}+b_{13} W^{2}+b_{14} C^{2}
\end{gathered}
$$

where $\mathrm{f}_{\mathrm{c} 28}$ is the 28 -days compressive strength ( $\left.\mathrm{MPa}\right), \mathrm{S}$ the measure of consistency (slump) (cm), A the air content (\%), W the water content $\left(\mathrm{Kg} / \mathrm{m}^{3}\right), \mathrm{C}$ the cement content $\left(\mathrm{Kg} / \mathrm{m}^{3}\right)$ and $b_{\mathrm{i}}$ are experimental parameters.

Thus $\quad \mathbf{a}=\left[b_{0} b_{1} b_{2} b_{3} b_{4} b_{5} b_{6} b_{7} b_{8} b_{9} b_{10} b_{11} b_{12} b_{13} b_{14}\right]$ and $X=[1$ S A W C SA SW SC $\mathrm{AW}$ AC WC S $\left.\mathrm{A}^{2} \mathrm{~W}^{2} \mathrm{C}^{2}\right]$

This full second order polynomial model is called full quadratic response surface (Model $\mathrm{N}^{\circ} 3$ in the following). By putting various coefficients equal to zero, several mathematical models are obtained:

- Pure quadratic if $\left[b_{5} b_{6} b_{7} b_{8} b_{9} b_{10}\right]=\overrightarrow{0}\left(\right.$ Model $\left.N^{\circ} 2\right)$

- Linear if $\left[b_{5} b_{6} b_{7} b_{8} b_{9} b_{10} b_{11} b_{12} b_{13} b_{14}\right]=\overrightarrow{0}\left(\right.$ Model $\left.N^{\circ} 1\right)$

The use of one of these models is conditioned on one hand by its mathematical properties and ability to fit data and on the other hand on the amount of available data: the more complex is the model the more data are needed to identify coefficients. 


\subsection{Architecture of Artificial Neural Network (ANN)}

In this work, we use another type of Meta-Model: the multi layer perceptron Artificial Neural Network method (ANN) with a back-propagation rule for the training. The objective is to estimate the compressive strength of the concrete too.

A typical ANN has three layers: the input layer, the hidden layer and the output layer. HechtNielsen (1991) proved that a three - layer feed - forward ANN could implement any function defined over a compact subset of Euclidean Space.

The inputs for the ANN are the slump, the content air, mixture of water and mixture of cement, while the output is the compressive strength of concrete at 28 days (Figure 2).

To establish this network we used $70 \%$ of the data bank in the training phase, $15 \%$ for the cross validation and $15 \%$ of the data bank are kept for the test phase.

For this, we chose a single architecture for ANN by using only one hidden layer (HEC 91), (WAN 99), (NIH 00) - to avoid the surapprentissage network while the number of neurons is equal to five, that is to say the sum of the neurons of input and output. Moreover, the update of the synaptic weights is done by packages; i.e. after each iteration. In addition, the hyperbolic tangent function is selected like function of activation of the hidden layer with a linear function for the output layer.

Fig. 2 The architecture of ANN network model.

\section{RESULTS AND ANALYSIS}

\subsection{Response surfaces model (RSM)}


Response surfaces have been fitted by using MATLAB software and the statistics Toolbox. First, let us consider a linear response surface function without interaction terms for which the nonzero coefficients are $b_{0}, b_{1}, b_{2}, b_{3}, b_{4}$ in Eq. (2). The form of this model, called Model $\mathrm{N}^{\circ} 1$, is the following

$$
\mathrm{f}_{\mathrm{c} 28}=43.1+0.31 \mathrm{~S}-1.15 \mathrm{~A}-0.33 \mathrm{~W}+0.16 \mathrm{C}
$$

Fig. 3. Effect of the slump, the air content, the water content and the cement content on the predicted concrete strength (Model $\mathrm{N}^{\circ} 1$ ).

Figure 3 shows the main trend (full line) of the evolution of the predicted concrete strength at 28 days according to the slump, the air content, the water content and the cement content: each trend according a given variable is obtained by fixing all others at their average value. Confidence interval (dashed line) are added. We notice a reduction in the concrete strength with the increase in the air content and the water content. On the other hand, when the slump and the cement content increase the concrete strength increases. Eq. (4) shows numerically to what extent an increase in the air and the water content decreases the concrete strength and an increase in the slump and the cement content increases the concrete strength.

The goodness of fit of Eq. (4) is characterized by the mean absolute value of the residual that is equal to 1.595 . It should be compared to those in the following obtained with other RSM model.

Second, a pure quadratic response surface function is considered for which non zero coefficients are $b_{0}, b_{1}, b_{2}, b_{3}, b_{4}, b_{5}, b_{6}, b_{7}, b_{8}, b_{9}, b_{10}$, in Eq. (2). The result is Model $N^{\circ} 2$ with the following form: 


$$
\begin{aligned}
\mathrm{f}_{\mathrm{c} 28} & =2.97+0.09 \mathrm{~S}-0.45 \mathrm{~A}-0.2 \mathrm{~W}+0.3 \mathrm{C}+ \\
& +0.012 \mathrm{~S}^{2}-0.016 \mathrm{~A}^{2}-0.0003 \mathrm{~W}^{2}-0.0002 \mathrm{C}^{2}
\end{aligned}
$$

Fig. 4. Effect of the slump, the air content, the water content and the cement content on the predicted concrete strength (Model $\left.\mathrm{N}^{\circ} 2\right)$.

The observations concerning figure 4 are identical to those corresponding to the model $\mathrm{N}^{\circ} 1$ except the increase of the confidence interval due to the fact that for a given amount of data the more the model is sophisticated the more is the uncertainty on its parameters.

The mean absolute value of the residual is 1.659 . It is very close to the one obtained with the linear model showing that no improvement is obtained with this type of model.

Third, a full quadratic response surface (in bold line) (with interaction terms) is fitted (Model $\mathrm{N}^{\circ} 3$ ). The form of this model is the following:

$$
\begin{gathered}
\mathrm{f}_{\mathrm{c} 28}=-31.57+2.63 \mathrm{~S}+43.52 \mathrm{~A}-0.27 \mathrm{~W}+0.29 \mathrm{C}+0.91 \mathrm{~S} \mathrm{~A}- \\
-0.028 \mathrm{SW}+0.002 \mathrm{SC}-0.2 \mathrm{AW}-0.0006 \mathrm{AC}-0.002 \mathrm{WC}+ \\
+0.096 \mathrm{~S}^{2}-2.36 \mathrm{~A}^{2}+0.0026 \mathrm{~W}^{2}+0.0003 \mathrm{C}^{2}
\end{gathered}
$$

Fig. 5. Effect of the slump, the air content, the water content and the cement content on the predicted concrete strength (Model $\left.\mathrm{N}^{\circ} 3\right)$.

The observations concerning figure 5 are identical to those corresponding to models 1 and 2 except that for the very firm concretes we have an increase in the compressive strength with 
decreases in slump which is not physically admissible. Moreover, the confidence interval is now very large and the mean absolute value of the residual is 18.832 meaning that the trend is less fitted.

\subsubsection{Three-D representation of results}

In view to best represent the interpolation capability of the full quadratic model in link with the data base we select two 3-D graphics respectively in space C-S-W (Figure 6) and C-A-W (Figure 7). Figures 6 and 7 show that the slump, the air content, the water content and the cement content are good indicators of the compressive strength of concrete. Colorbar allows showing the range of values given by the model according to these coordinates when isolated black points show the position of experimental data. Note that for each graph the predictive value is computed by considering the mean value of the missed variable respectively $\underline{\mathrm{A}}$ and $\underline{\mathrm{S}}$, $\underline{A}=1.6577$ and $\underline{S}=6.5202$, like illustrated in the figures 3,4 and 5 .

Fig. 6. 3-D graphics respectively in space Cement content-Slump-Water content.

Fig. 7. 3-D graphics respectively in space Cement content-Air content-Water content.

\subsubsection{Comparison of the experimentally obtained compressive strengths to corresponding values estimated by the RSM}

A comparison was made between the compressive strengths obtained by the RSM and the experimentally values measured. The goodness of fit of Model $\mathrm{N}^{\circ} 1$ (see Eq.(4)) is characterized by $\mathrm{R}^{2}=0.9476$, as well as graphically in Figure 8 . Figure 9 and Figure 10 plot the same experimental values with a comparison with Model $\mathrm{N}^{\circ} 2$ (see Eq.(5)) and 3 (see 
Eq.(6)) respectively. It can be seen from the comparison of Figures 8, 9 and 10, as well as from the correlation coefficients, that the goodness of fit of Eq.(5): (a) is better than that of Eq.(6), and (b) is very close to the one obtained with the linear model that is Eq.(4).

Fig. 8. Comparison of the measured compressive strengths to corresponding values estimated by the formula of Model $\mathrm{N}^{\circ} 1$.

Fig. 9. Comparison of the measured compressive strengths to corresponding values estimated by the formula of Model $\mathrm{N}^{\circ} 2$.

Fig. 10. Comparison of the measured compressive strengths to corresponding values estimated by the formula of Model $N^{\circ} 3$.

\subsection{Artificial Neural Network (ANN)}

\subsubsection{Comparison of the experimentally obtained compressive strengths to corresponding values estimated by the ANN}

A comparison was made between the compressive strengths obtained by the ANN network model and the experimentally values measured. The results of the training and the cross validation are presented in the Figures 11a and 11b. These Figures reveal a very strong correlation with $\mathrm{R}^{2}=0.9569$ for the training and $\mathrm{R}^{2}=0.9596$ for the validation where $\mathrm{R}$ is the linear correlation coefficient. These coefficients inform us about the good total quality of the training and the validation and both RSM and ANN are good Meta-Models. The quadratic errors, for their parts, are very small and are about 0.01 . 
Fig. 11a. Estimated and measured compressive strengths (training phase).

Fig. 11b. Estimated and measured compressive strengths (phase of validation cross).

Thereafter, a test was carried out by making the comparison between the measured compressive strengths and those estimated by ANN network model, by using compressive strengths which do not belong to the data base of the training and the validation. The test was made with $15 \%$ of the total data base. This comparison (Figure 12) reveals a very strong correlation with $\mathrm{R}^{2}=0.9807$. Moreover, the quadratic error is about 0.01 .

Fig. 12. Estimated and measured compressive strengths (test phase).

\subsection{Comparison and analysis}

Figures $8,9,10,11$ and 12 show that the fits of RSM models are very close to the one of ANN network model. It also can be seen from the $\mathrm{R}^{2}$ values that the RSM models (Model $\mathrm{N}^{\circ} 1$ and Model $\mathrm{N}^{\circ} 2$ ) are as good as the ANN network model.

Table 1. Relative error relating between the measured compressive strengths at 28 days to corresponding values estimated by ANN network model and RSM models.

From an analysis of the relative errors, it can be noted that the modelling results are reasonably good, especially the ones in Table 1 corresponding to model ANN and models RSM (Model $\mathrm{N}^{\circ} 1$ and Model $\mathrm{N}^{\circ} 2$ ), whereas, the error relative of model $\mathrm{N}^{\circ} 3$ is higher.

\section{CONCLUSIONS}


From the numerical modelling and the experiment tests done, which constituted a considerable experimental work (approximately 800 cylindrical specimens 16x32 cm were made), one can draw up the list of the following conclusions:

- The concretes considered here cover an extremely broad range of strength from $12.1 \mathrm{MPa}$ to concretes of $40.9 \mathrm{MPa}$ intended for the reinforced concrete structures building or public works and this for a strength class of 32.5. These concretes have presented good rheological properties at the fresh state, and could be used to manufacture under good conditions various specimens.

- The new Meta-Models (RSM or ANN) are well supported by the large group of experimental data. They are shown to improve the computerized proportioning as well as strength prediction of concrete. Equally, or perhaps even more important, however, is that the method presented in this paper offers a better insight into the concrete strength-versuscomposition relation-ship through the presented implications of these formulas or models.

- The goodness of fit of equations of models 1, 2 and 3 are characterized by the mean absolute value of the residual that is equal to 1.595 for model $\mathrm{N}^{\circ} 1$, equal to 1.659 for model $\mathrm{N}^{\circ} 2$, It is very close to the one obtained with the linear model (1) and equal to 18.832 for model $\mathrm{N}^{\circ} 3$. These new analytical models provide an improved tool for the prediction of concrete strength and for concrete proportioning.

- The validation of the artificial neural network model (ANN) is carried out with data not used before. This validation is carried out by confronting the values of the strengths estimated by ANN network model and those actually measured. The results obtained show, the 
convergence of the compressive strengths at 28 days estimated towards those measured. The relative error relating between the compressive strengths at 28 days estimated by ANN network model and those measured hardly exceeds an average of $4.74 \%$.

- ANN network model was constructed for provide a quick mean of predicting 28-day compressive strength of concrete based on some of its influence factors. This computational intelligent method will be helpful to civil engineers, technologists, ready-mix operators and concrete mixture designers in civil engineering and concrete mixing and batching plants. ANN network model attain good prediction accuracy. Some effects of concrete compositions on strength are in accordance with the rules of mix proportioning. Consequently, the application of RSM or ANN network model to concrete strength prediction is practical and has a good future depending on the goal:

- RSM is very tractable for sensitivity analysis and comparisons because its formulation is explicit and derivatives can be computed;

- ANN allows us to introduce new information with time and up-date the modelling.

\section{REFERENCES}

Abrams, L.D. 1919, (1981), "Properties of concrete", cited by Neville A.M., $3^{\text {rd }}$ ed, Pitman.

AFNOR. (2002), “Concrete and its constituents. Tome 1: Specifications of concrete and its constituents", 5e edition, Paris, 431 p. (In French)

Algerian Standards (1992), publishing and distribution by Abou Hamou Moussa, Algiers. (In French)

Baroth, J., Schoefs, F. \& Breysse, D. (2011), “Construction Reliability: safety, randomness, maintenance, security”, ISTE Willey, In Press. 
Boukli Hacene, S.M.A. \& Ghomari, F. (2007), "Study of the compression resistance of local concretes", Twelfth International Colloquium on Structural and Geotechnical Engineering, ICSGE, Cairo, Egypt, 10-12 December, pp.1005-1014.

Boukli Hacene, S.M.A., Ghomari, F. \& Khelidj, A. (2009), "Compressive Strengths of Concrete Formulated with Algerian Local Materials", Jordan Journal of Civil Engineering, Volume 3, No. 2, April, pp.103-117.

Boukli Hacene, S.M.A., Ghomari F., Schoefs F. \& Khelidj A. (2009), "Experimental study and statistics of the influence of slump and air content on the compressive strength of concrete”, Lebanese Science Journal, Volume 10, No. 2, October, pp.81-100. (In French)

Faravelli, L. (1989), "Response-Surface Approach for Reliability Analysis”, J.Engrg. Mech. 115, 2763; doi: 10.1061/ (ASCE) 0733-9399(1989)115:12(2763), 19 pages.

Favre, J.L. (2004), "Safety of Buildings, Risks. Modeling uncertainty, reliability, risk analysis", Edition Ellipses, Paris. (In French)

Feret, R. (1892), “On the compactness of the mortars”, Annales des Ponts et Chaussées, Série 7, Vol. 4, pp. 5-164. (In French)

Ferkous, S., Houari H., Chikh N. \& Mouatsi M. (1999), "Durability of concretes: report, causes and remedies", Proceedings of the Second National Seminar of Civil Engineering, Mentouri University, Constantine, 24-25 may. (In French)

Hecht-Nielsen R. (1991), Theory of the Back - Propagation Neural Network, in: H. Wechsler (Ed.), Neural Networks for Perception, Vol. 2, Aca- demic Press, San Diego, CA, pp. 65-93.

Labeyrie, J. (1997), Response Surface Methodology in Structural Reliability. Probabilistic Methods for Structural Design, C. Guedes Soares (Ed.), Solid Mechanics and its Applications, Vol. 56, Kluwer Academic Publishers, pp. 39-58. 
Leira, B.J., Holmås T. \& Ferfjord, K. (2003), "Response Surface Parametrization for $\mathrm{C}=300 \mathrm{~kg} / \mathrm{m}^{3}$

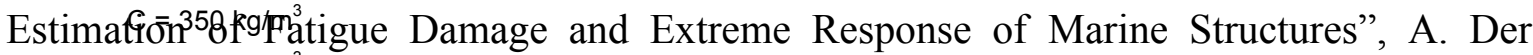
$\mathrm{C}=400 \mathrm{ka} / \mathrm{m}^{3}$

Kiureghian, S. Madanat and J.M. Pestana ed., 9th Int. Conf. on Application of Statistics and Probability in Civil Engineering, (ICASP9), Vol. 1, Theme E "Damage and Deterioration", Millpress Rotterdam, pp. 589 - 598.

Neville, AM. (1995), "Properties of concrete”, Longman, Harlow.

Ni H.G. \& Wang J.Z. (2000), "Prediction of compressive strength of concrete by neural networks", Cement and Concrete Research, 30, pp. 1245-1250, June.

Popovics, S. \& Popovics J. (1995), “Computerisation of the Strength versus W/C Relationship", Concrete International, vol. 17, N4, pp. 37-40, April.

Wang J.Z. \& Ni H.G. (1999), "Prediction of compressive strength of cement based upon BP neural networks", J Chin Ceram Soc 27 (4), pp. 408-414.

Schoefs F. (2008), "Sensitivity approach for modelling the environmental loading of marine structures through a matrix response surface", Reliability Engineering and System Safety, Available online 19 June 2007, Vol. 93, Issue 7, July, pp. 1004-1017, doi: dx.doi.org/10.1016/j.ress.2007.05.006.

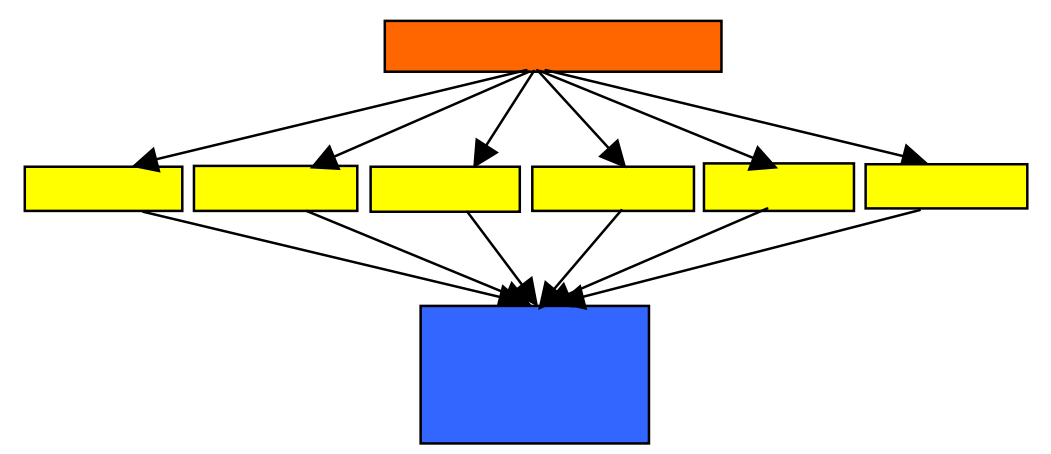

Fig. 1. Organigram of the experimental program. 


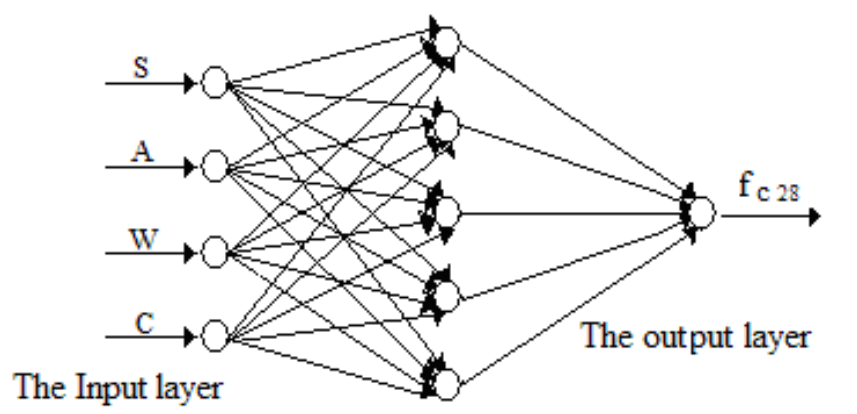

S : Slump

A : Air content

W: Dosage of water

C: Dosage of cement

$f_{c 28}: 28 d$ compressive strength of concrete

The hidden layer

Fig. 2 The architecture of ANN network model.

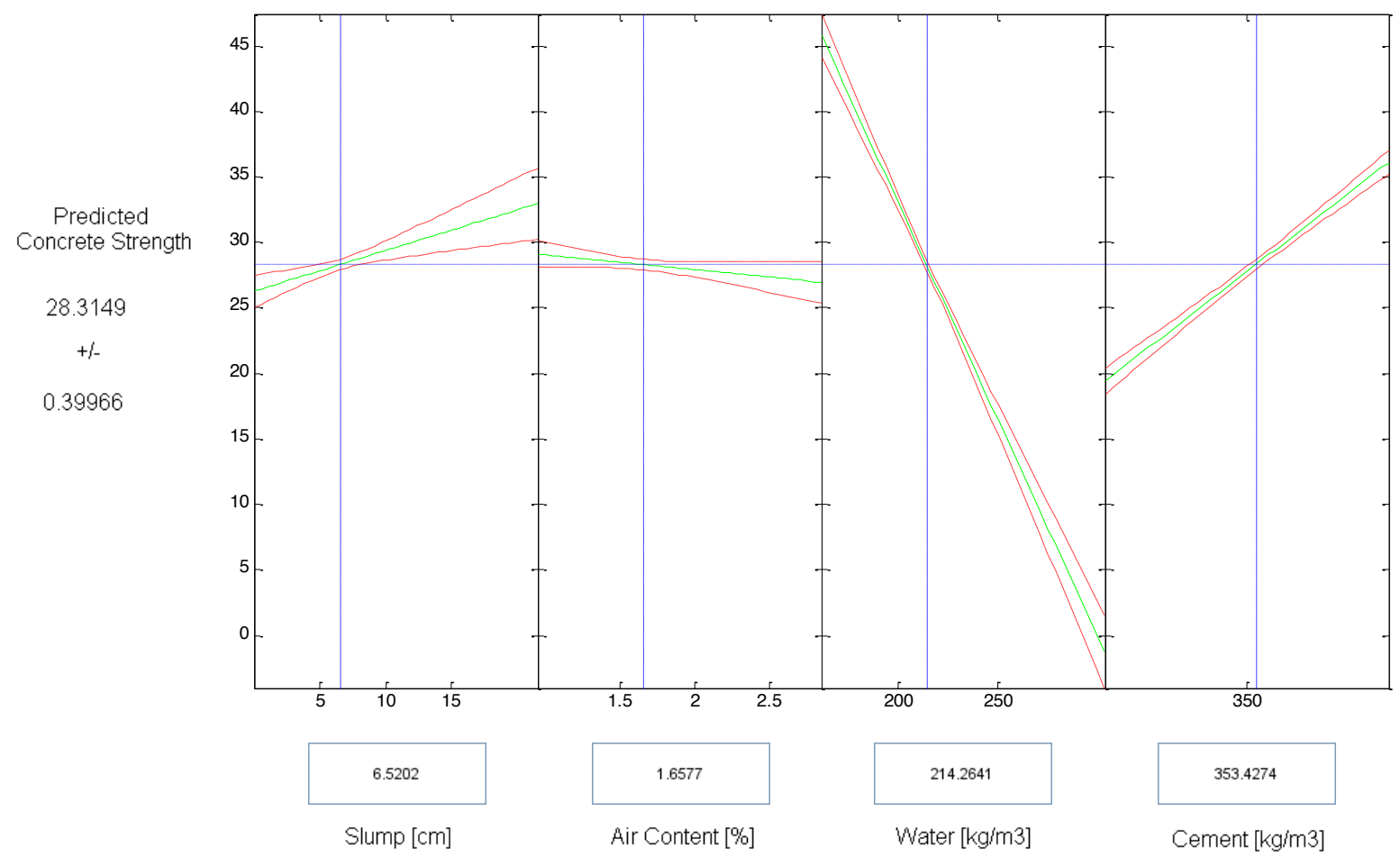

Fig. 3. Effect of the slump, the air content, the water content and the cement content on the predicted concrete strength (Model $\mathrm{N}^{\circ} 1$ ). 


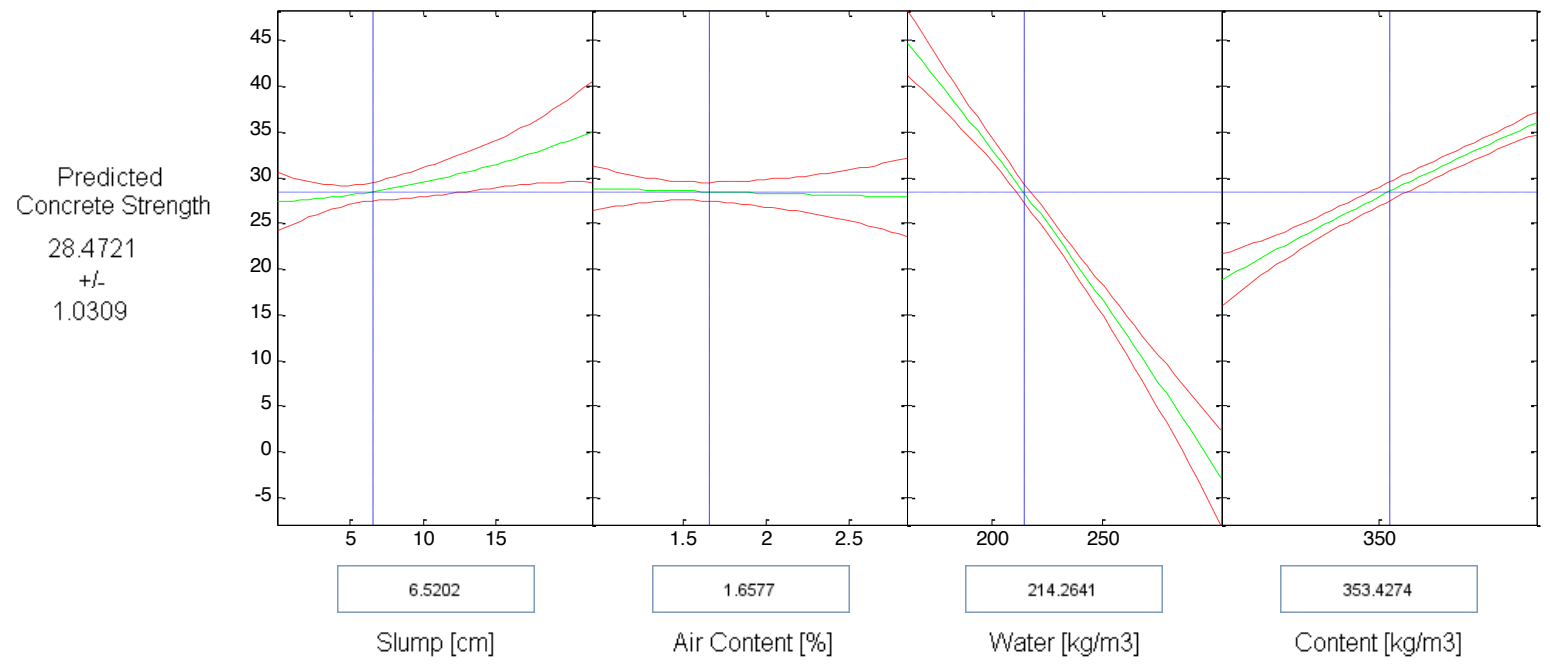

Fig. 4. Effect of the slump, the air content, the water content and the cement content on the predicted concrete strength (Model $\mathrm{N}^{\circ} 2$ ).

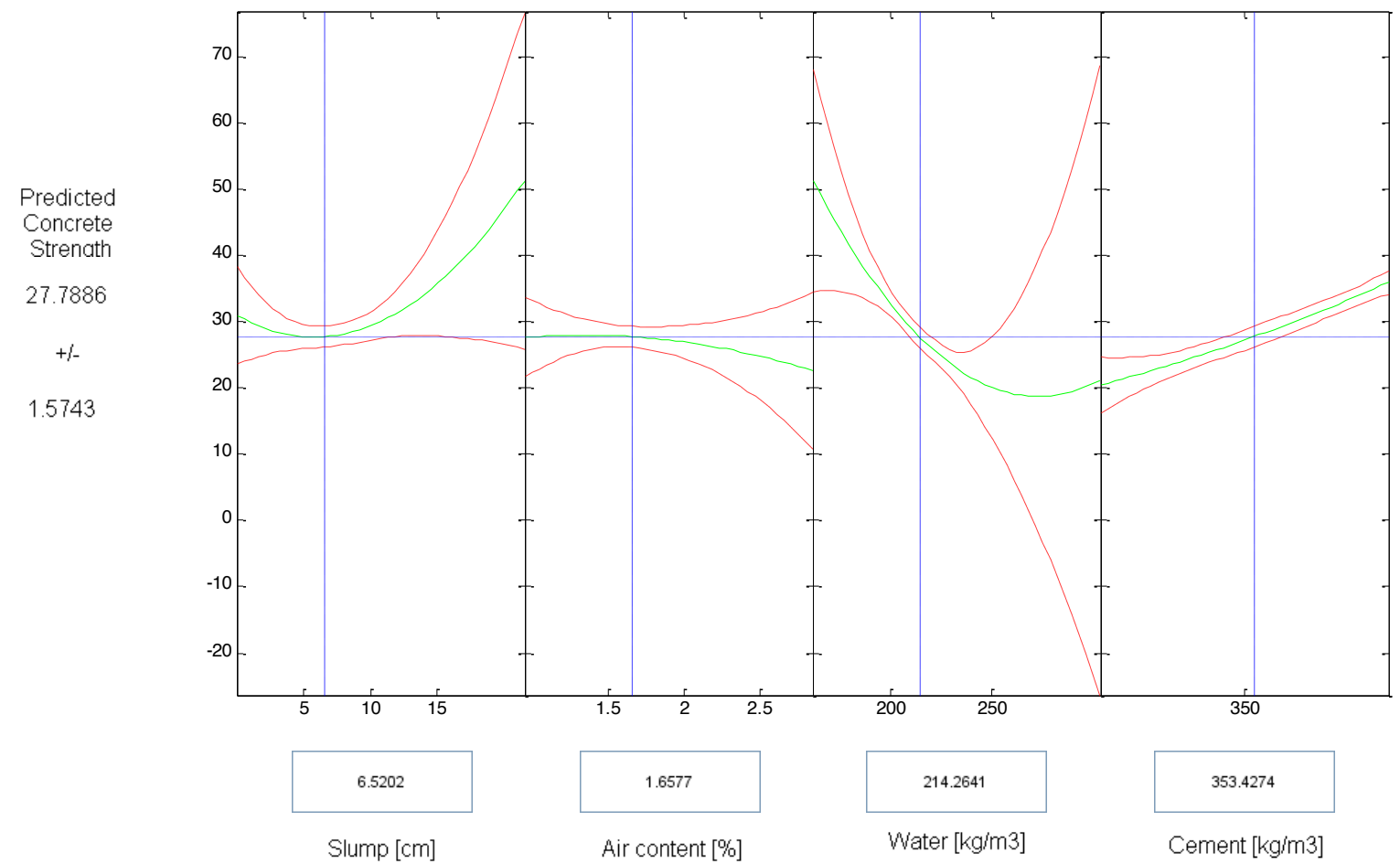

Fig. 5. Effect of the slump, the air content, the water content and the cement content on the predicted concrete strength (Model $N^{\circ} 3$ ). 


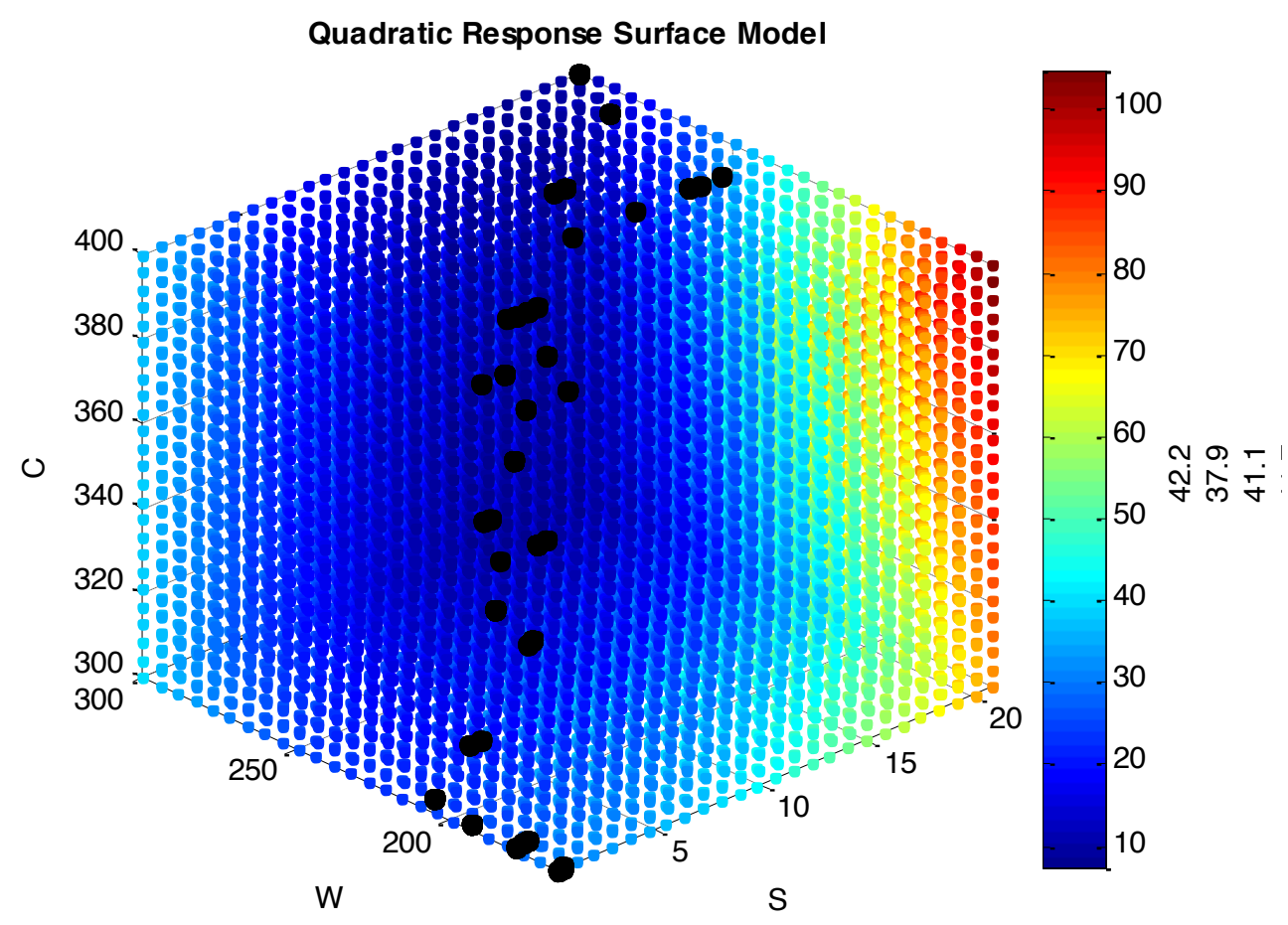

Fig. 6. 3-D graphics respectively in space Cement content-Slump-Water content.

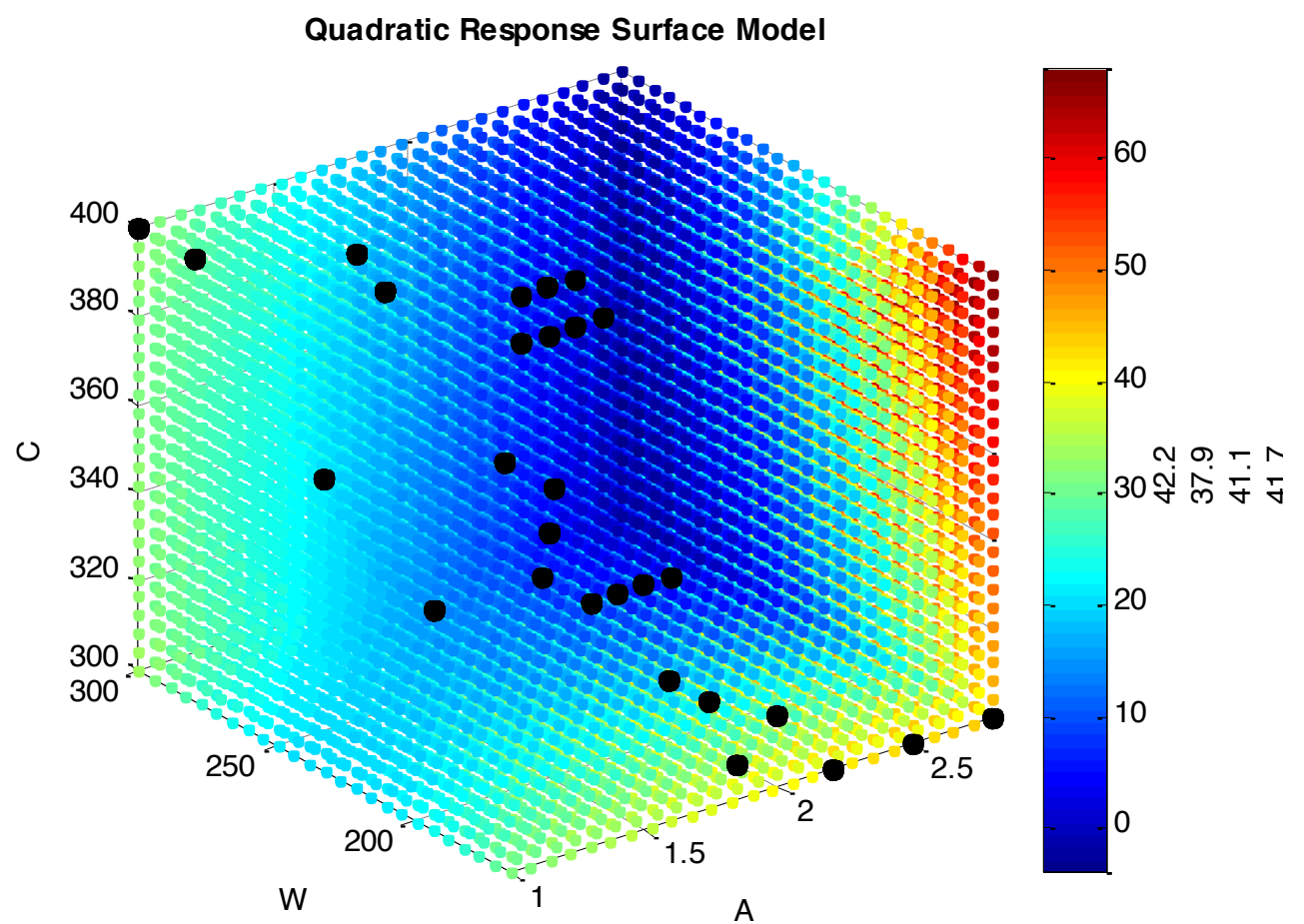

Fig. 7. 3-D graphics respectively in space Cement content-Air content-Water content. 


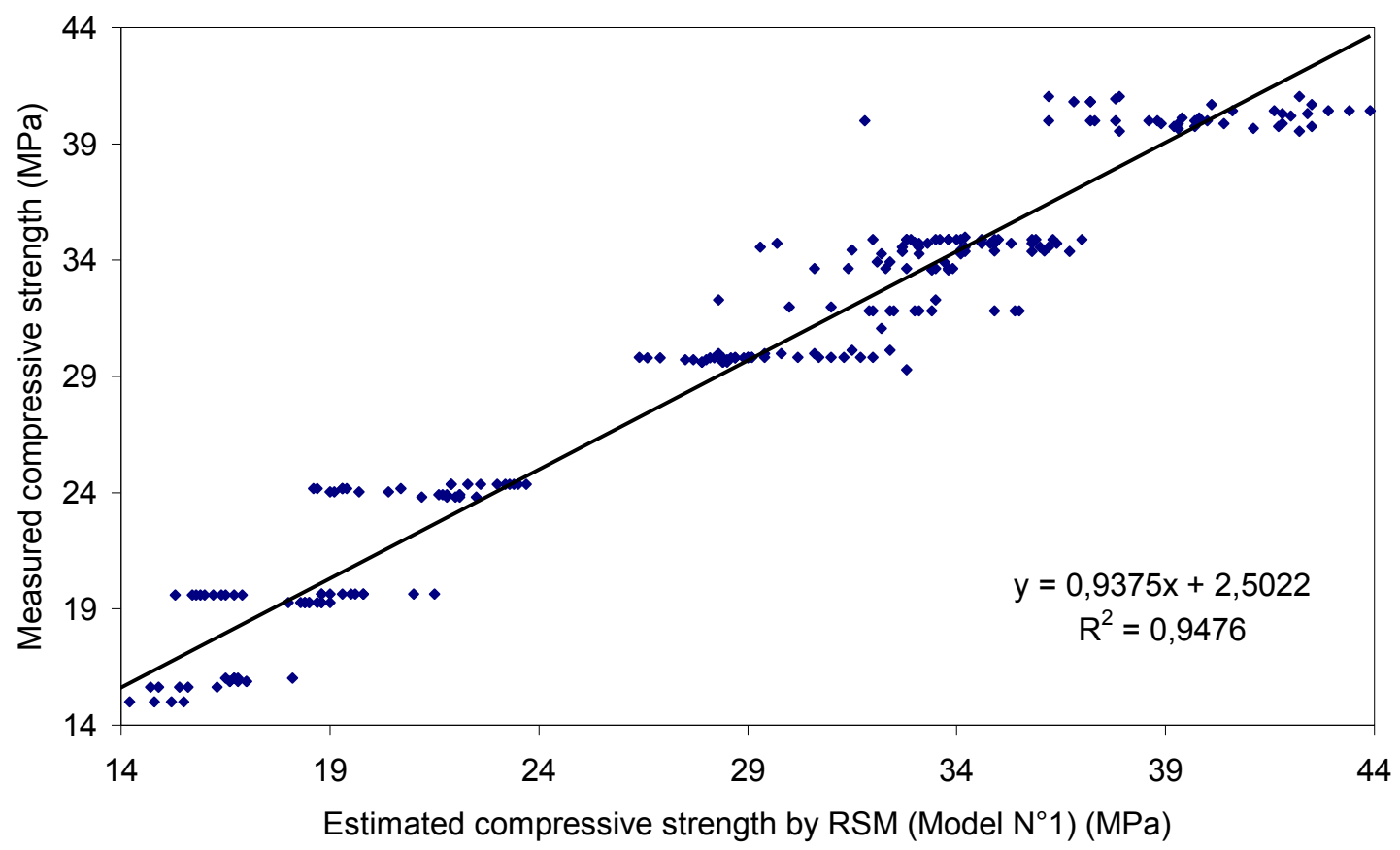

Fig. 8. Comparison of the measured compressive strengths to corresponding values estimated by the formula of Model $\mathrm{N}^{\circ} 1$.

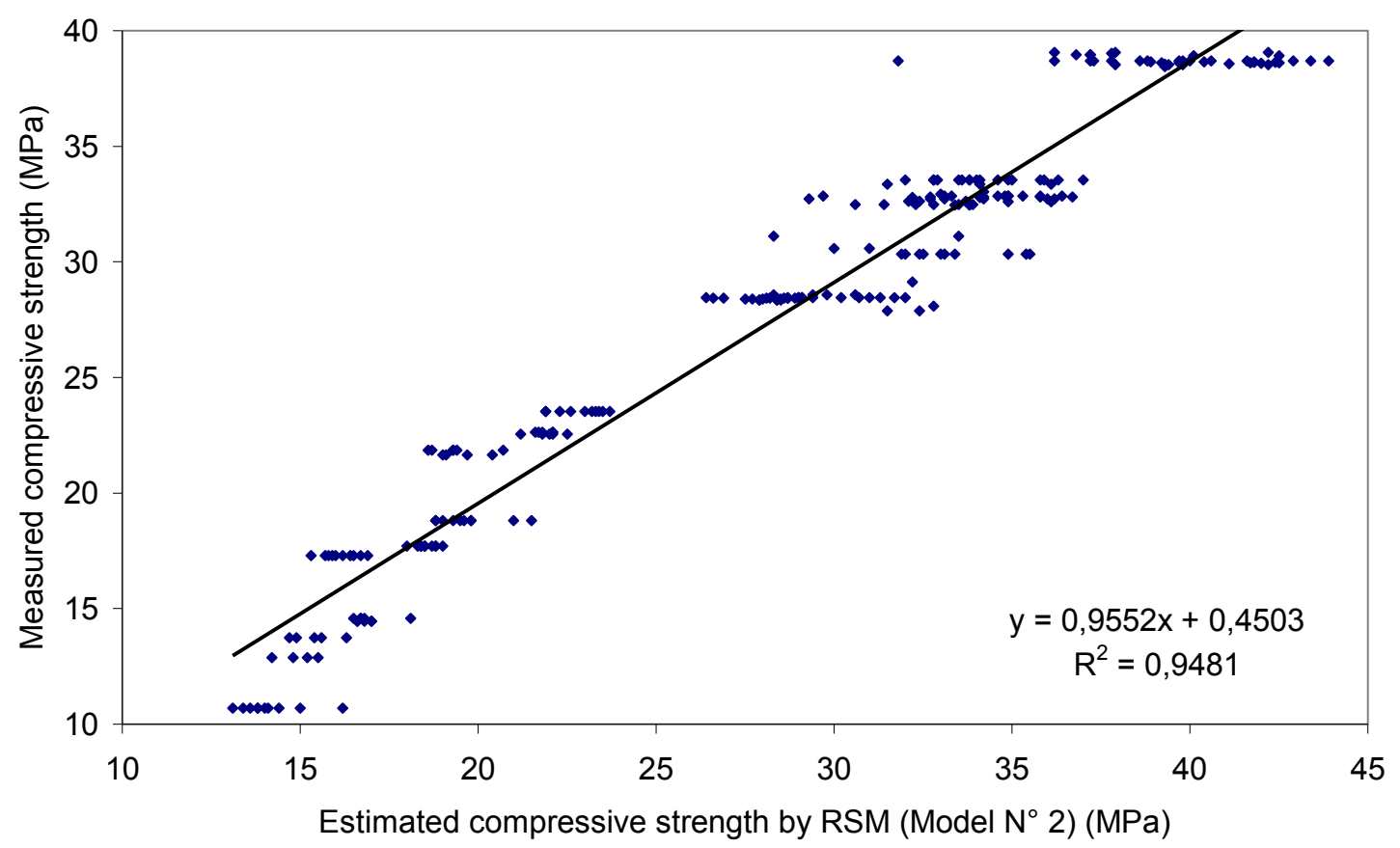

Fig. 9. Comparison of the measured compressive strengths to corresponding values estimated by the formula of Model $\mathrm{N}^{\circ} 2$. 


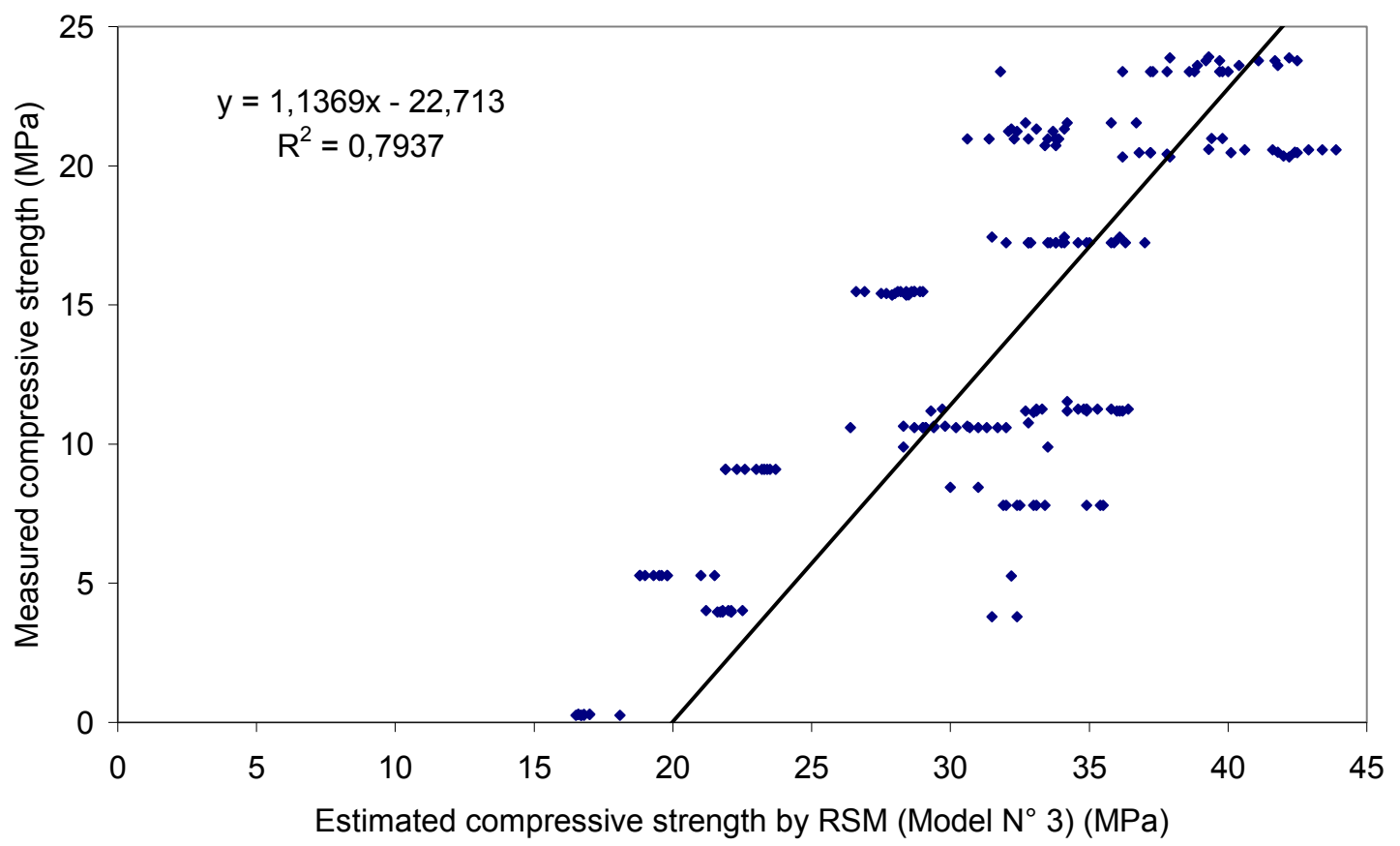

Fig. 10. Comparison of the measured compressive strengths to corresponding values estimated by the formula of Model $\mathrm{N}^{\circ} 3$.

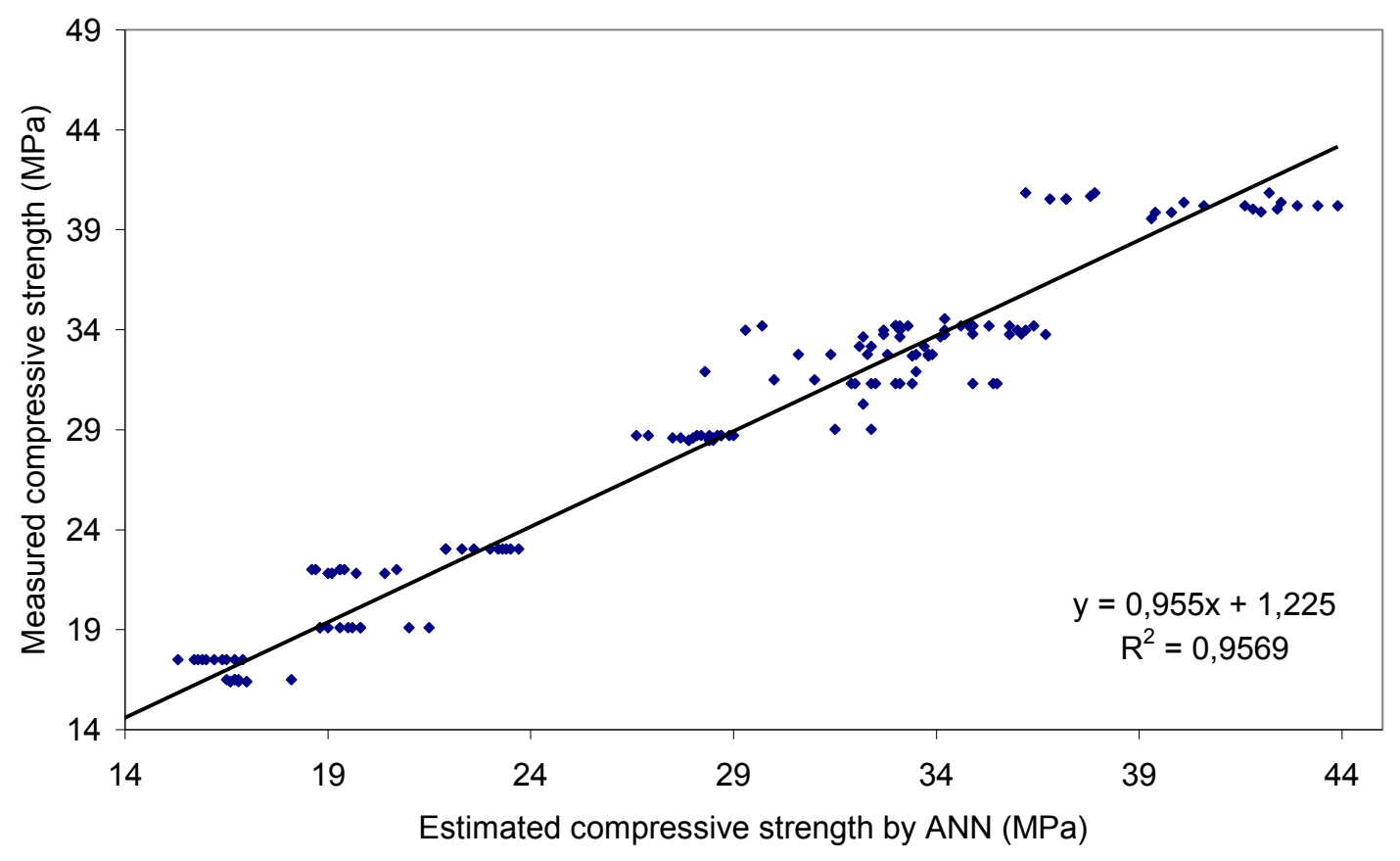

Fig. 11a. Estimated and measured compressive strengths (training phase). 


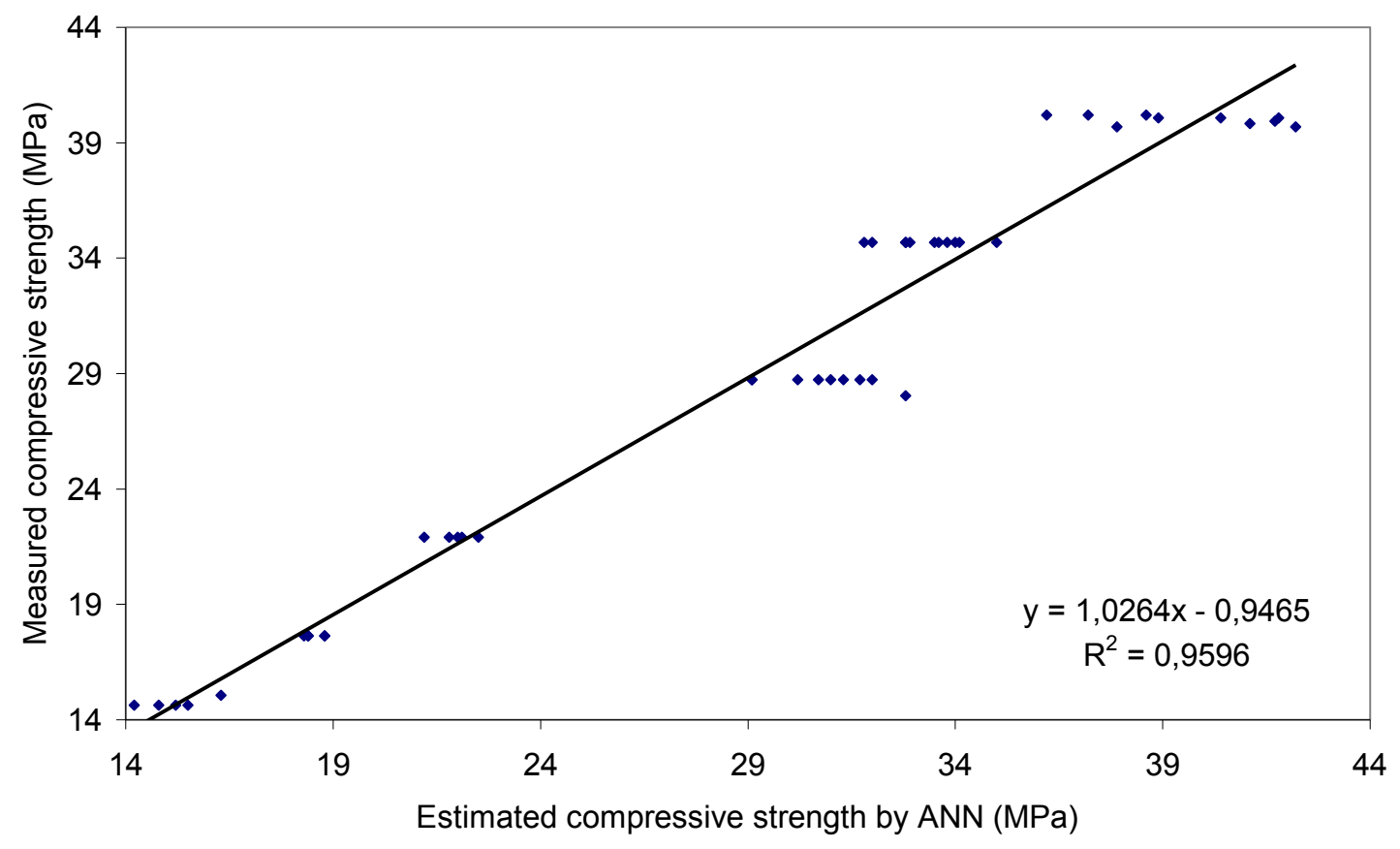

Fig. 11b. Estimated and measured compressive strengths (phase of validation cross).

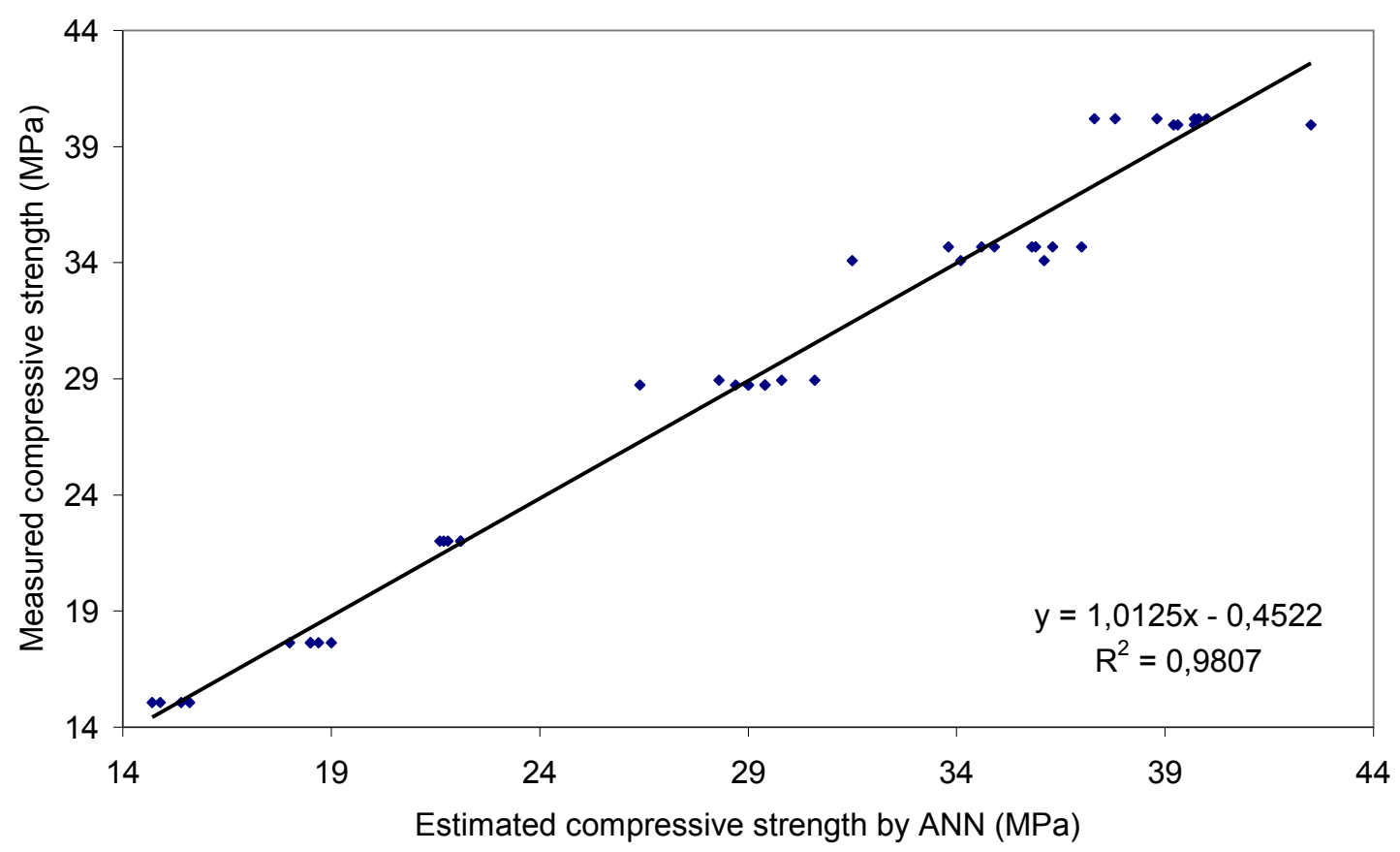

Fig. 12. Estimated and measured compressive strengths (test phase) 
Table 1. Relative error relating between the measured compressive strengths at 28 days to corresponding values estimated by ANN network model and RSM models.

\begin{tabular}{ccccc}
\hline \multirow{2}{*}{ Models } & ANN & \multicolumn{3}{c}{ RSM } \\
\cline { 3 - 5 } & & $\mathrm{N}^{\circ} 1$ & $\mathrm{~N}^{\circ} 2$ & $\mathrm{~N}^{\circ} 3$ \\
\hline Relative error (\%) & 4.74 & 6.28 & 6.51 & 76.4 \\
\hline
\end{tabular}

